\title{
Phenol adsorption on different nano-sized carbon materials: first comparative study
}

\author{
Bartosz Kruszka $^{1}$ - Marek Wiśniewski ${ }^{1,2} \cdot$ Artur P. Terzyk $^{1}$
}

Received: 11 September 2015/Revised: 2 October 2015/Accepted: 5 October 2015/Published online: 13 October 2015

(C) The Author(s) 2015. This article is published with open access at Springerlink.com

\begin{abstract}
Carbon nanofibres and multi-branched carbon nanotubes are synthesized by using a new, proposed in this study method. The acid-base, adsorption and geometric properties of nanomaterials are characterised. Next we present first comparative adsorption and calorimetric studies of phenol uptake from aqueous solutions on mentioned nano-sized carbon materials and on nanotubes having similar diameter. The comparison of carbon nanofibres, multi-branched carbon nanotubes, and multi walled carbon nanotubes shows that for non-porous carbon nanomaterials the concentration of basic surface functionalities determines the mechanism of phenol adsorption. In consequence, larger phenol adsorption is recorded for the most basic nanomaterials (nanofibres and multi walled nanotubes) and smaller for multi branched nanotubes having the smallest surface concentration of basic groups. Possible explanation of differences between enthalpy of phenol displacement on graphite and on studied carbon adsorbents is also given.
\end{abstract}

Keywords Carbon nanomaterials - Synthesis · Nanotubes · Nanofibres · Phenol adsorption - Energetics of adsorption

Artur P. Terzyk

aterzyk@chem.umk.pl;

http://www.chem.uni.torun.pl/ aterzyk/

1 Department of Chemistry, Faculty of Chemistry, Physicochemistry of Carbon Materials Research Group, Nicolaus Copernicus University in Toruń, Gagarin St. 7, 87-100 Toruń, Poland

2 INVEST-TECH R\&D Center, 32-34 Plaska St., 87-100 Toruń, Poland

\section{Introduction}

The phenomenon of phenol adsorption from aqueous solutions is very important mainly due to ecological reasons, and it has been studied for many years. In this field carbon adsorbents are the most effective and this is why they are applied in water plant stations. On the other hand, the new nanocarbon materials have been synthesized, and there are reports showing phenol adsorption results, for example, on carbon nanotubes (Nie et al. 2011; Toth et al. 2011, 2012; Li et al. 2013; Wang et al. 2011; Lin and Xing 2008; Yang et al. 2008). Recently Chakraborty et al. (2011) proved that carbon nanofibre based adsorbents can also be successfully applied as phenol adsorbents.

Multibranched carbon nanotubes are very important carbon nanomaterials due to their unique electric, mechanical and transport properties (Saito et al. 1998; Papadopoulos et al. 2000; Tao et al. 2005). Recently Jia et al. (2013) synthesized unbranched and branched carbon nanotubes by catalytic chemical vapor deposition from methane at $1173 \mathrm{~K}$ using a $\mathrm{Cu} / \mathrm{MgO}$ catalyst. Also Tao et al. (2005) synthesized novel multi-branched carbon nanotubes using alkali-element modified $\mathrm{Cu} / \mathrm{MgO}$ catalyst. Pyrolysis of thiophene (Romo-Herrera et al. 2008) was also an important method to prepare branched CNTs. Other methods to fabricate branched CNTs include arc discharge (Wang et al. 2006), carbon dioxide reduction (Lou et al. 2006), and chemical vapor deposition (CVD).

Next nano-sized form of carbon are carbon nanofibres. They can be divided into platelet, herring-bone and tubular types (Inagaki and Kang 2014). Recent progress in the synthesis of nanofibrs are given in the subsequent reports (Davoodi et al. 2013; Retterer et al. 2008; Röthlisberger et al. 2013; Longtin et al. 2007; Tu et al. 2003; Pan et al. 2005; Hashempour et al. 2014; Lee et al. 2008; Tao et al. 
2006; Chai et al. 2007; Yamada et al. 2006; Lee et al. 2001; Thakur et al. 2010; Ghavaninia et al. 2011).

We mention above different nano-sized forms of carbon since in this study we show a new method of synthesis of multi-branched carbon nanotubes and carbon nanofibres. Next, we present a comparative study of phenol adsorption on those materials and on multi-walled carbon nanotubes having similar average diameter. Up to our knowledge, the results of calorimetric studies of phenol adsorption from solutions on studied carbon nanomaterials are new and have not been published in literature yet. Also in literature there is a lack of comparative studies on phenol adsorption on different nanoforms of carbon.

\section{Experimental}

\subsection{Carbon nanomaterials}

All synthesis reactions were conducted in two types i.e., horizontal $(h)$ and vertical $(v)$ quartz tube furnaces using super growth chemical vapour deposition (SGCVD) methods (Zhao et al. 2009; Chiang et al. 2011; Yasuda et al. 2009; Futaba et al. 2009; Yamada et al. 2008; Kruszka et al. 2014). The investigations were conducted on stainless steel foils. Before all processes a metal film was cleaned in methanol (all samples) and additionally in a concentrated sulphuric acid for different oxidation times. We concluded that the oxidation time of $24 \mathrm{~h}$ is the most promising, thus we studied in detail the process of synthesis on stainless steel samples modified in this way.

The process was carried out at $1173 \mathrm{~K}$ for all studied systems. The temperatures as well as the flow rates were optimised experimentally. After the suitable temperature was reached the process of synthesis was started using appropriate gases: (i) $\mathrm{CH}_{4}$ for the flow rate $15 \mathrm{ml} / \mathrm{min}$, (ii) $\mathrm{N}_{2}-17 \mathrm{ml} / \mathrm{min}$, (iii) $\mathrm{H}_{2}$ $34 \mathrm{ml} / \mathrm{min}$, (iv) $\mathrm{H}_{2} \mathrm{O}$, and (v) $\mathrm{CH}_{3} \mathrm{OH}$. Time of reaction $\left(t_{r}\right)$ was about $30 \mathrm{~min}$. After the process was finished the reactor was filled with nitrogen for about $1 \mathrm{~h}$. We obtained CNFs and MBCNTs at the same conditions, the only difference is that CNFs are obtained in a horizontal furnace, while MBCNTs a vertical one. For comparative purposes we also study Bayer closed carbon nanotubes (BayTubes $\mathrm{C150HP}$ ) purchased from Bayer Material Science (Germany). They are used without further purification (and labelled as B_MWCNTs).

\subsection{Characterisation}

In order to characterize the structure of studied nanomaterials $\mathrm{N}_{2}$ adsorption-desorption isotherms at $77 \mathrm{~K}$ were measured using ASAP 2010 (Micromeritics) sorption apparatus. From obtained data the BET surface area values were calculated.
Boehm titration method was carried out to determine the surface acidity and basicity (Boehm 2002; Boehm et al. 1964). Additionally, the $\mathrm{pH}$ levels of carbon nanomaterials were measured used standard method (Biniak et al. 1997).

The nonpolarized Raman scattering spectra of carbon structures were investigated in the spectral range of $100-3200 \mathrm{~cm}^{-1}$. Raman spectra were recorded in the backscattering geometry using Perkin-Elmer Raman-Micro 200 system. As an excitation light we used the near-infrared laser operating at $785 \mathrm{~nm}, \mathrm{CCD}$ matrix detector cooled to $223 \mathrm{~K}$. The laser beam was tightly focused on the sample surface through a Leica $\times 20$ SWD microscope objective (SWD-short working distance). To prevent any damage to the sample, an excitation power was fixed at $8 \mathrm{~mW}$. The position of the microscope objective with respect to the sample was piezoelectrically controlled (XY position). The reference position (level 0) was assumed for the laser spot focused on the surface of the sample. The micro-Raman spectrometer allowed for recording of the Raman spectra with spatial resolution of about $10 \mu \mathrm{m}$ and spectral resolution about $3 \mathrm{~cm}^{-1}$. To increase the signal-tonoise ratio, accumulation of Raman spectra was made ten times.

\subsection{Flow calorimetric and adsorption from aqueous solution measurements}

Four solutions of phenol having the concentration in the range $0.0002-0.011 \mathrm{~mol} / \mathrm{dm}^{3}$ were prepared at $300 \mathrm{~K}$. The values of differential enthalpy of displacement were measured using a flow calorimetric system constructed in our laboratory based on (Rhue et al. 2002) and described previously (Wiśniewski et al. 2015) by changing the flow from one solution to another (in rising and decreasing order, during adsorption and desorption, respectively). A fixed mass of carbon material (ca. $90 \mathrm{mg}$ ) was placed inside the chamber and thermostated in flow of water $(50 \mathrm{~g} / \mathrm{h})$. A pair of thermistors, one upstream and the other downstream from the sample, formed one-half of an electronic bridge and sensed temperature changes in the solution as it passed through the sample. A change in solution temperature produced a differential output voltage from the bridge. This differential voltage was fed into an instrumentation amplifier, and the amplified signal was fed into a computer for processing. The system possessed high sensitivity, low thermal drift, and a good signal-to-noise ratio. Six way valve was used to switch water into the solution containing phenol. Flow rates $(50 \mathrm{~g} / \mathrm{h})$ were controlled with mass flow controllers with the accuracy less than $0.1 \%$. All measurements were performed at $300 \mathrm{~K}$. Connection of flow system on-line to the UV-Vis spectrophotometer (JASCO V-660, Japan) was used $(\lambda=270 \mathrm{~nm})$ to guarantee the quantitative analysis of the observed phenomena. 


\section{Results and discussion}

Table 1 collects the results of carbon nanomaterials characterization. As one can see from this Table, and from the analysis of additional results, the diameter as well as the purity of all studied materials are similar (ca. $15 \mathrm{~nm}$ and $95 \%$, respectively). The largest surface area is observed for MBCNTs, while for the remaining materials smaller (and similar) values are recorded. Calculated per surface area concentration of acidic groups is the highest for CNFs. Also CNFs and B_MWCNTs contain the largest concentration of basic groups. The comparison of suspension $\mathrm{pH}$ values leads to the conclusion that the strongest basic groups are present on the surface of MBCNTs.

Figures 1, 2, and 3 collect the high resolution scanning electron microscopy (HRSEM) images of all three studied

Table 1 Selected characteristics of studied nanometarials

\begin{tabular}{lllllllll}
\hline Nanomaterial & $\begin{array}{l}\text { Diameter } \\
(\mathrm{nm})\end{array}$ & $\begin{array}{l}\mathrm{S}_{\mathrm{BET}} \\
\left(\mathrm{m}^{2} / \mathrm{g}\right)\end{array}$ & $\begin{array}{l}\text { Suspension } \\
\mathrm{pH}\end{array}$ & $\begin{array}{l}\text { Total acidity } \\
(\mathrm{mmol} / \mathrm{g})\end{array}$ & $\begin{array}{l}\text { Total basicity } \\
(\mathrm{mmol} / \mathrm{g})\end{array}$ & $\begin{array}{l}\text { Total acidity } \\
\left(\mathrm{mmol} / \mathrm{m}^{2}\right)\end{array}$ & $\begin{array}{l}\text { Total basicity } \\
\left(\mathrm{mmol}^{4} / \mathrm{m}^{2}\right)\end{array}$ & $\begin{array}{l}\mathrm{I}_{\mathrm{d}} / \mathrm{I}_{\mathrm{g}} \\
\text { ( }\end{array}$ \\
\hline CNFs & $15-20$ & 207 & 7.73 & 0.5020 & 0.8015 & 24.25 & 38.72 & 1.05 \\
B_MWCNTs & $\sim 15$ & 198 & 6.89 & 0.1048 & 0.7677 & 5.29 & 38.77 & 2.05 \\
MBCNTs & $\sim 15$ & 310 & 8.67 & 0.1066 & 0.7445 & 3.43 & 24.02 \\
\hline
\end{tabular}
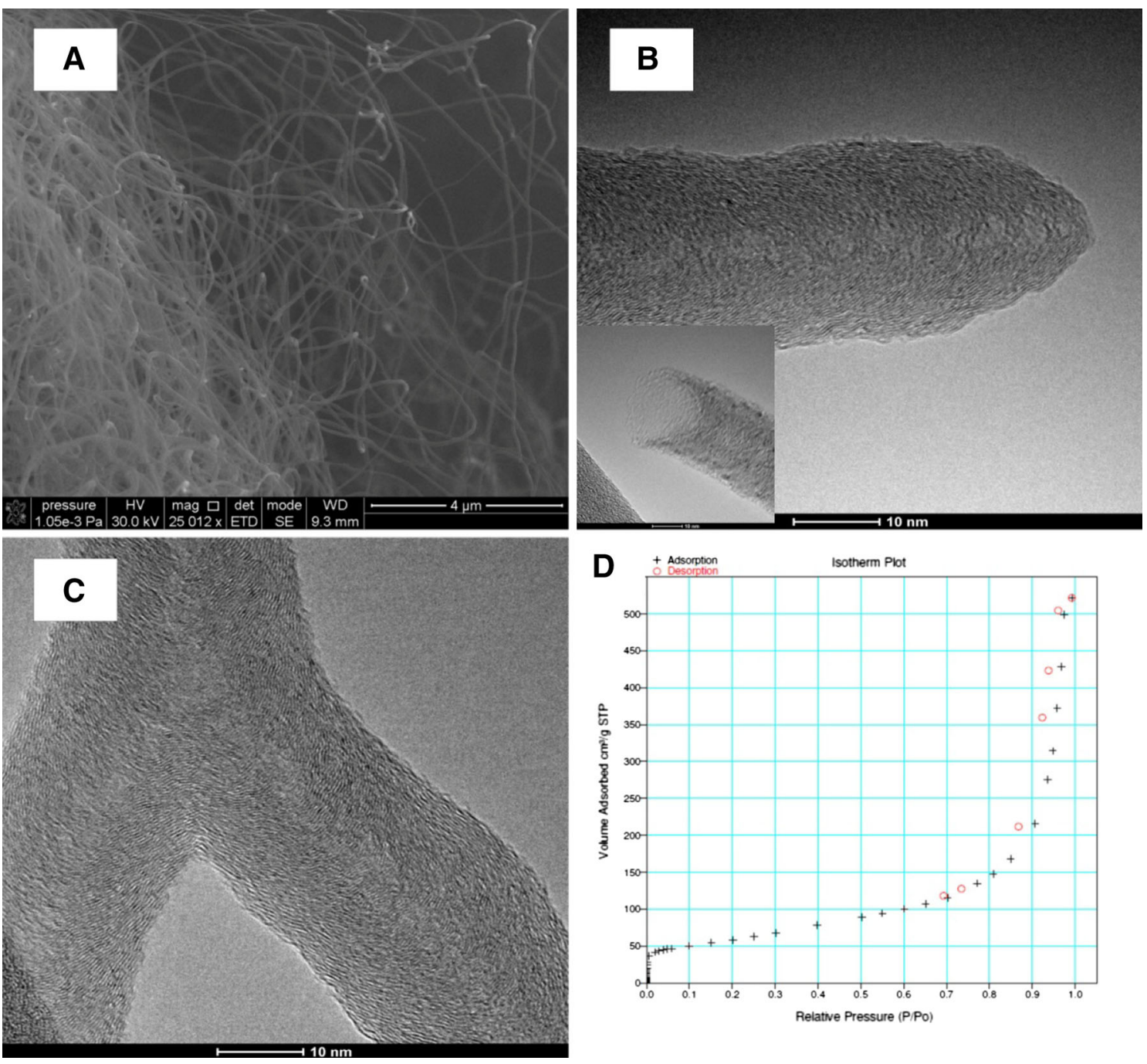

Fig. 1 HRSEM image results for synthesis of CNFs on metal film in various conditions using horizontal furnace (pre-treated concentrated sulphuric acid for $24 \mathrm{~h}$ ): a HRSEM and b, c HRTEM images-

$\mathrm{T}=1173 \mathrm{~K},\left(\mathrm{SGCVD}-\mathrm{H}_{2} \mathrm{O}+\mathrm{H}_{2}+\mathrm{CH}_{4}+\mathrm{CH}_{3} \mathrm{OH}, t_{r}=30 \mathrm{~min}\right)$. d Adsorption-desorption isotherm plot for obtained CNFs, BET specific surface area is equal to $207 \mathrm{~m}^{2} / \mathrm{g}$ 

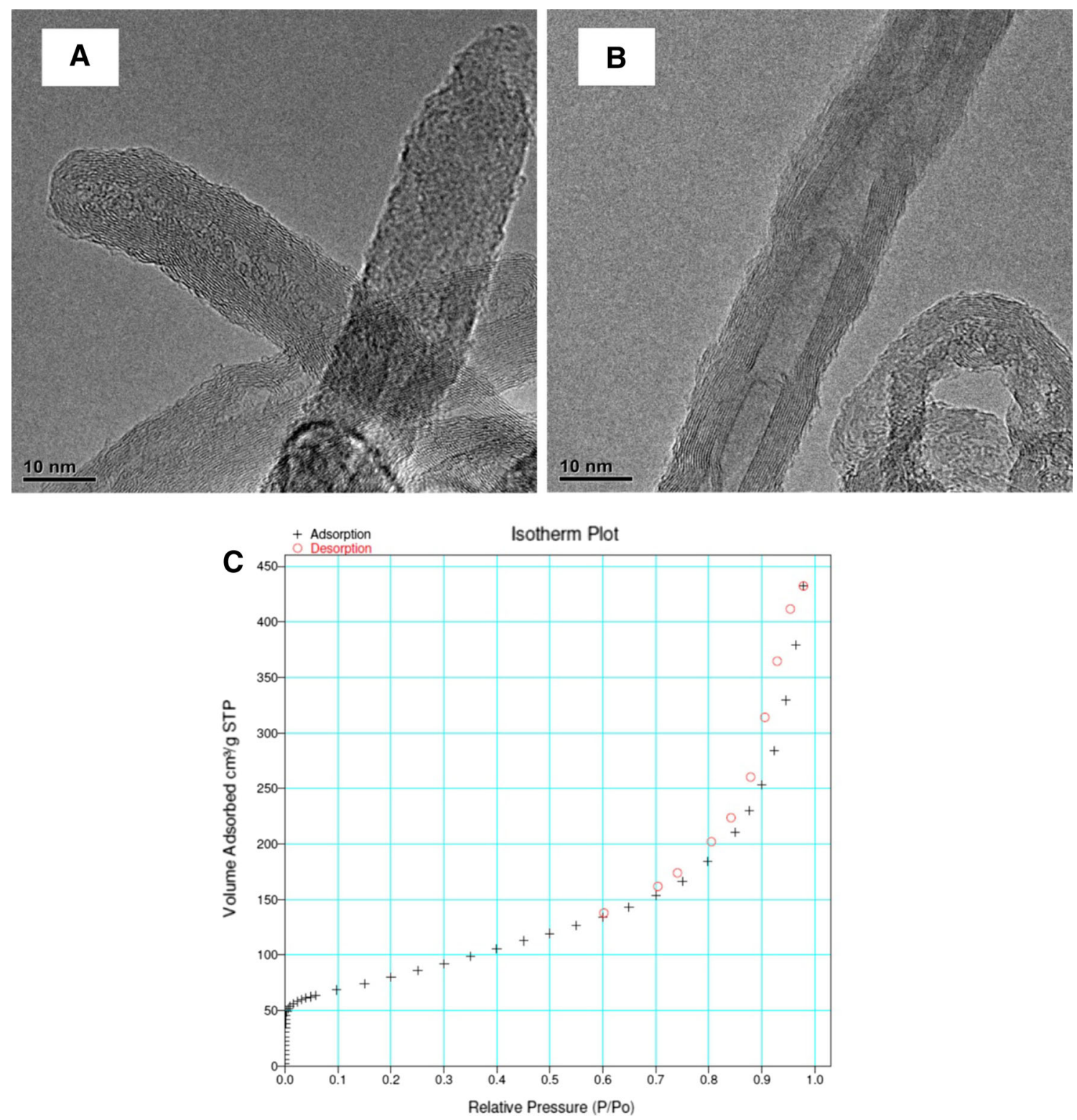

Fig. 2 a, b HRTEM images for commercial B_MWCNTs, c Adsorption-desorption isotherm plot for B_MWCNTs, BET specific surface area is equal to $198 \mathrm{~m}^{2} / \mathrm{g}$

samples together with low-temperature $\mathrm{N}_{2}$ adsorption-desorption data. All samples contain some amount of mesopores as a results of the presence of so-called secondary porosity. One can see that CNFs (Fig. 1) are of tubular type (Inagaki and Kang 2014), resembling B_MWCNTs (Fig. 3). In contrast, MBCNTs (Fig. 2) are very similar to those synthesized by Tao et al. (2005). They have typical secondary branches forming so-called "Y junctions". This is why the surface area of MBCNTs is remarkably larger than this observed for CNFs and B_MWCNTs (Table 1). The latter two materials have similar surface area values.

Figure 4 collects the comparative plots of adsorption isotherms and enthalpy of displacement. Since the differences between adsorption and desorption are in the range of experimental errors we show only adsorption data. It should be noted that adsorption values at low concentration determined by us for CNFs are similar to those measured by Rokhina et al. for modified commercial nanofibres (Rokhina et al. 2012). On the other hand, for adsorption on B_MWCNTs we observe similar results to published by Lin and Xing (2008).

From Fig. 4 it can be seen that the largest adsorption occurs for the materials containing the largest concentration of surface basic groups (B_MWCNTs and CNFs). The same can be stated about the values of displacement enthalpy. One can see that the most exothermic effect is observed for B_MWCNTs and CNFs, while slightly smaller enthalpy is recorded for MBCNTs. Generally, 

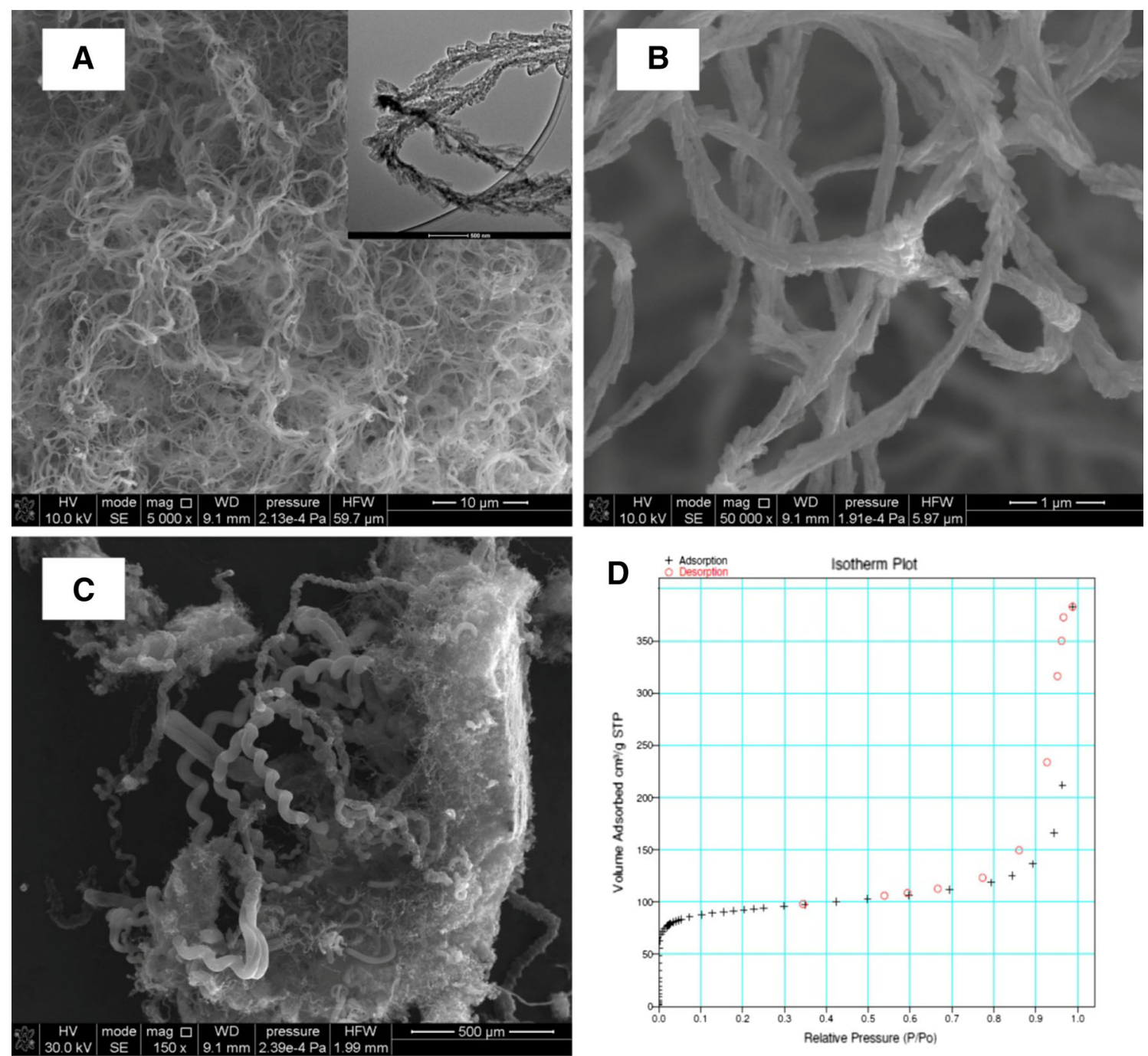

Fig. 3 HRSEM and HRTEM image results for synthesis of MBCNTs on metal film in various conditions using vertical furnace (pre-treated concentrated sulphuric acid for $24 \mathrm{~h}$ ): a-c HRSEM images and inset in

a. HRTEM image-T $=1173 \mathrm{~K},\left(\mathrm{SGCVD}-\mathrm{H}_{2} \mathrm{O}+\mathrm{H}_{2}+\mathrm{CH}_{4}+\right.$ $\mathrm{CH}_{3} \mathrm{OH}, t_{r}=30 \mathrm{~min}$ ). d Adsorption-desorption isotherm plot for obtained MBCNTs, BET specific surface area is equal to $310 \mathrm{~m}^{2} / \mathrm{g}$

maximum values of phenol displacement enthalpy in monolayer are in the range of ca. $-20 \mathrm{~mJ} / \mathrm{m}^{2}$. On the other hand, in the polymolecular region this enthalpy is between -10 and $-20 \mathrm{~kJ} / \mathrm{mol}$. Comparison of obtained results with the data published for phenol adsorption on graphite (Király et al. 1996) shows that in the case of phenol adsorption on new nano-sized carbon materials adsorption is remarkably larger than on graphite, and both values i.e., the enthalpy of displacement in monolayer as well as the enthalpy of displacement in polymolecular range, are smaller than the values recorded for graphite. Possible explanation of this can be obtained from the analysis of the points responsible for "monolayer" creation. Assuming the monolayer creation at the intersection points of the enthalpy plots (Fig. 4) (Király et al. 1996) the following specific surface areas of phenol molecule are calculated: 833.3, 952.4 and $571.4 \mathrm{~m}^{2} / \mathrm{mmol}$ for adsorption on

MBCNTs, CNFs and B_MWCNTs, respectively. On the other hand, reported by Király et al. (1996) specific surface areas for "flat" orientation of adsorbed phenol molecule are in the range $345-326 \mathrm{~m}^{2} / \mathrm{mmol}$. Thus for all studied carbon nano-forms remarkably larger values than those reported in Király et al. (1996) are observed. Even for B_MWCNTs the value of specific surface area is c.a. $60 \%$ too large to assume perfect "flat" orientation. Since all values are too large the only possible explanation is the presence of water in "monolayer" of adsorbed molecules. In fact, the results of our recent MD simulations proved that water is present and no "tight" monolayer is created on surface of nanotubes during adsorption from solution (Terzyk et al. 2009). Instead of this phenol molecules form spiral structures wrapping nanotubes. Summing up, our experimental results show that water islands on surface of nanomaterials are formed. From Table 1 one can see that 

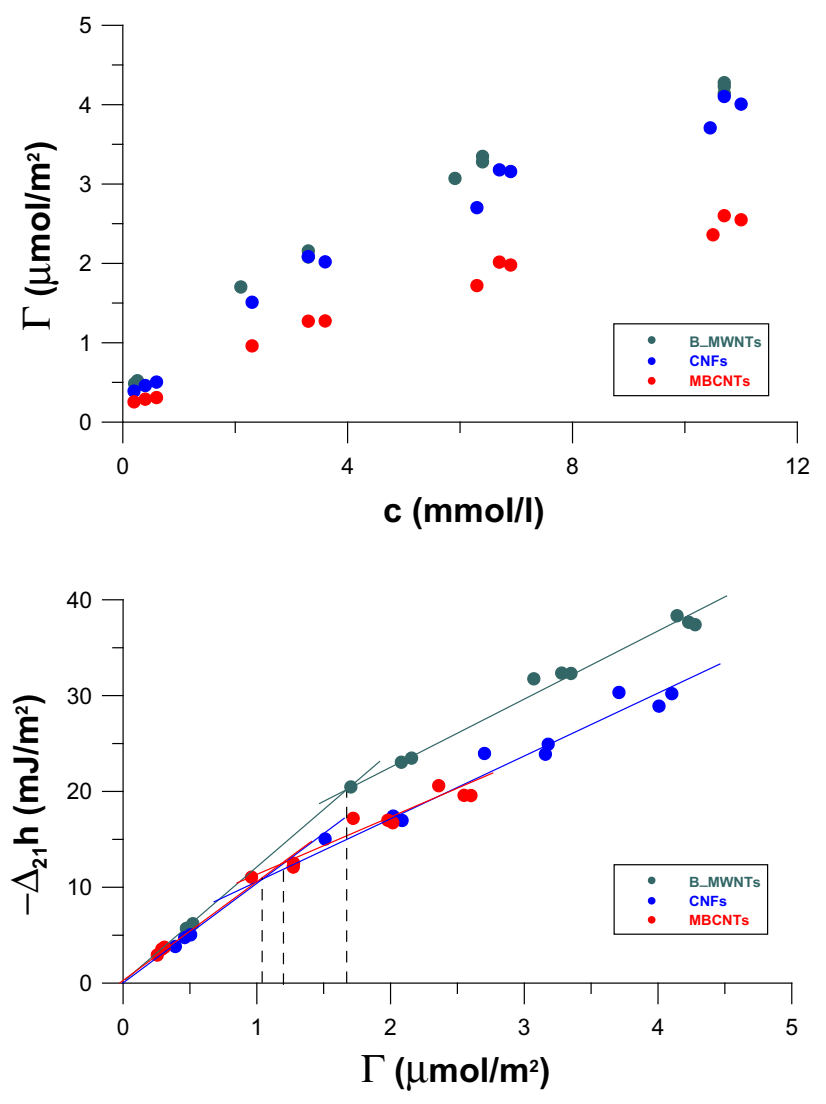

Fig. 4 Phenol adsorption isotherms and integral enthalpy of displacement

on the surface of CNFs the largest concentration of acidic groups occurs, and probably this causes the value of specific surface area of adsorbed phenol molecules the largest. Taking into account the data collected in Table 1 one can conclude that the highest adsorption, as well as the most exothermic effect, are observed for adsorbents having the largest concentration of surface basic groups. This means that the interaction between hydrogen of hydroxylic group and the basic sites present on surface increase adsorption. The $\mathrm{I}_{\mathrm{d}} / \mathrm{I}_{\mathrm{g}}$ ratio collected in Table 1 is the largest for B_MWCNTs and this can suggest that in this case basic sites are of Lewis type, and those sites are located on $\mathrm{p}$ orbitals of carbon nanomaterial. For all studied nanomaterials the enthalpy of adsorption in the first layer is not so exothermic as in the case of adsorption on graphite. This can be caused by nano-sized carbon materials surface curvature (Wiśniewski et al. 2015), the presence of surface acidic groups making the energy of water displacement larger and therefore the process of displacement not so exothermic as in the case of graphite, and finally, by smaller degree of graphitisation decreasing the energy of $\pi-\pi$ interactions. However, to decide which effect predominates further studies are necessary.

\section{Conclusions}

We show that the treatment of stainless steel foils with conc. $\mathrm{H}_{2} \mathrm{SO}_{4}$, and the application of the SGCVD method leads to the synthesis of carbon nanofibres and multibranched carbon nanotubes. The type of applied furnace has a crucial influence on the type of obtained nano-sized carbon material.

Comparative results of phenol adsorption on nano-sized carbon materials as reported for the first time. We show that the process is fully reversible and surface concentration of basic groups increases phenol adsorption as well as the exothermicity of displacement process. Finally it is concluded that the presence of surface acids causes the formation of water islands on surface, and this is why the specific surface areas of adsorbed phenol are larger than for perfect "flat" orientation observed for adsorption on graphite. Interactions between phenol and surface bases cause that the adsorption values for all studied nanomaterials are larger than those observed for adsorption on graphite, and this makes studied carbon nanoforms promising for further application in the phenol adsorption process.

Acknowledgments Scientific work is being financed from the budget Resources on Science in 2012-2015 as the research project Diamond Grant 0361/DIA/2012/41 (Bartosz Kruszka).

Open Access This article is distributed under the terms of the Creative Commons Attribution 4.0 International License (http://crea tivecommons.org/licenses/by/4.0/), which permits unrestricted use, distribution, and reproduction in any medium, provided you give appropriate credit to the original author(s) and the source, provide a link to the Creative Commons license, and indicate if changes were made.

\section{References}

Biniak, S., Szymanski, G., Siedlewski, J., Swiątkowski, A.: The characterization of activated carbons with oxygen and nitrogen surface groups. Carbon 35(12), 1799-1810 (1997)

Boehm, H.P.: Surface oxides on carbon and their analysis: a critical assessment. Carbon 40(2), 145-149 (2002)

Boehm, H.P., Diehl, E., Heck, W., Sappok, R.: Surface oxides of carbon. Angew. Chem. Int. Ed. 3(10), 669-677 (1964)

Chai, S.P., Zein, S.H.S., Mohamed, A.R.: Synthesizing carbon nanotubes and carbon nanofibers over supported-nickel oxide catalysts via catalytic decomposition of methane. Diam. Relat. Mat. 16(8), 1656-1664 (2007)

Chakraborty, A., Deva, D., Sharma, A., Verma, N.: Adsorbents based on carbon microfibers and carbon nanofibers for the removal of phenol and lead from water. J. Colloid Interface Sci. 359(1), 228-239 (2011)

Chiang, W.H., Futaba, D.N., Yumura, M., Hata, K.: Growth control of single-walled, double-walled, and triple-walled carbon nanotube forests by a priori electrical resistance measurement of catalyst films. Carbon 49(13), 4368-4375 (2011)

Davoodi, M.A., Towfighi, J., Rashidi, A.: Facile synthesis of carbon nanotube/nanofiber paper on a water-soluble support in one-step 
by chemical vapor deposition. Chem. Eng. J. 221, 159-165 (2013)

Futaba, D.N., Goto, J., Yasuda, S., Yamada, T., Yumur, M., Hata, K.: A background level of oxygen-containing aromatics for synthetic control of carbon nanotube structure. J. Am. Chem. Soc. 131(44), 15992-15993 (2009)

Ghavanini, F.A., Lopez-Damian, M., Rafieian, D., Svensson, K., Lundgren, P., Enoksson, P.: Controlling the initial phase of PECVD growth of vertically aligned carbon nanofibers on TiN. Sens. Actuators A Phys. 172(1), 347-358 (2011)

Hashempour, M., Vicenzo, A., Zhao, F., Bestetti, M.: Effects of CVD direct growth of carbon nanotubes and nanofibers on microstructure and electrochemical corrosion behavior of 316 stainless steel. Mater. Charact. 92, 64-76 (2014)

Inagaki, M., Kang, F.: Graphene derivatives: graphane, fluorographene, graphene oxide, graphyne and graphdiyne. J. Mater. Chem. A 2(33), 13193-13206 (2014)

Jia, Y., Wu, P.Y., Fang, F., Zhou, S.S., Peng, D.Y.: Synthesis and characterization of unbranched and branched multi-walled carbon nanotubes using $\mathrm{Cu}$ as catalyst. Solid State Sci. 18, 71-77 (2013)

Király, Z., Dékány, I., Klumpp, E., Lewandowski, H., Narres, H.D., Schwuger, M.J.: Selective sorption of phenol and related compounds from aqueous solutions onto graphitized carbon black. Adsorption and flow microcalorimetric studies. Langmiur 12(2), 423-430 (1996)

Kruszka, B., Terzyk, A.P., Wiśniewski, M., Gauden, P.A., Szybowicz, M.: Synthesis of carbon nanotubes and nanotube forests on copper catalyst. Mater. Res. Express 1, 035040 (2014)

Lee, K.Y., Fujimoto, K., Ohkura, S., Honda, S., Katayama, M., Hirao, T., Oura, K.: Synthesis of vertically aligned carbon nanofiber films by RF magnetron sputtering. MRS Proc. (2001). doi:10. 1557/PROC-675-W3.1.1

Lee, S., Choi, S., Park, K.H., Chae, K.W., Cho, J.B., Ahn, Y., Park, J.Y., Koh, K.H.: Hot-filament CVD synthesis and application of carbon nanostructures. Thin Solid Films 516(5), 700-705 (2008)

Li, M., Hsieh, T.C., Doong, R.A., Huang, C.P.: Tuning the adsorption capability of multi-walled carbon nanotubes to polar and nonpolar organic compounds by surface oxidation. Sep. Purif. Technol. 117, 98-103 (2013)

Lin, D., Xing, B.: Adsorption of phenolic compounds by carbon nanotubes: role of aromaticity and substitution of hydroxyl groups. Environ. Sci. Technol. 42(19), 7254-7259 (2008)

Longtin, R., Fauteux, C., Goduguchinta, R., Pegna, J.: Synthesis of carbon nanofiber films and nanofiber composite coatings by laser-assisted catalytic chemical vapor deposition. Thin Solid Films 515(5), 2958-2964 (2007)

Lou, Z., Chen, C., Huang, H., Zhao, D.: Fabrication of Y-junction carbon nanotubes by reduction of carbon dioxide with sodium borohydride. Diam. Relat. Mater. 15(10), 1540-1543 (2006)

Nie, J.Q., Zhang, Q., Zhao, M.Q., Huang, J.Q., Wen, Q., Cui, Y., Qian, W.Z., Wei, F.: Synthesis of high quality single-walled carbon nanotubes on natural sepiolite and their use for phenol absorption. Carbon 49(5), 1568-1580 (2011)

Pan, C., Liu, Y., Cao, F.: Novel solid-cored carbon nanofiber grown on steels substrates in ethanol flames. J. Mater. Sci. Lett. 40(5), 1293-1295 (2005)

Papadopoulos, C., Rakitin, A., Li, J., Vedeneev, A.S., Xu, J.M.: Electronic transport in Y-junction carbon nanotubes. Phys. Rev. Lett. 85(16), 3476-3479 (2000)

Retterer, S.T., Melechko, A., Hensley, D.K., Simpson, M.L., Doktycz, M.J.: Positional control of catalyst nanoparticles for the synthesis of high density carbon nanofiber arrays. Carbon 46(11), 1378-1383 (2008)
Rhue, D.R., Appel, C.S., Kabengi, N.J.: Measuring surface chemical properties of soil using flow calorimetry. Soil Sci. 167, 782-790 (2002)

Rokhina, E.V., Lahtinen, M., Makarova, K., Jegatheesan, V., Virkutyte, J.: Theoretical and practical aspects of chemical functionalization of carbon nanofibers (CNFs): DFT calculations and adsorption study. Bioresour. Technol. 113, 127-131 (2012)

Romo-Herrera, J.M., Sumpter, B.G., Cullen, D.A., Terrones, H., Cruz-Silva, E., Smith, D.J., Meunier, V., Terrones, M.: An atomistic branching mechanism for carbon nanotubes: sulfur as the triggering agent. Angew. Chem. Int. Ed. 47(16), 2948-2953 (2008)

Röthlisberger, A., Seita, M., Reiser, A., Shawat, E., Spolenak, R., Nessim, G.D.: Investigating the mechanism of collective bidirectional growth of carbon nanofiber carpets on metallic substrates. Carbon 63, 498-507 (2013)

Saito, R., Dresselhaus, G., Dresselhaus, M.S.: Physical properties of carbon nanotubes. Imperial College Press, London (1998)

Tao, X., Zhang, X., Cheng, J., Wang, Y., Liu, F., Luo, Z.: Synthesis of novel multi-branched carbon nanotubes with alkali-element modified $\mathrm{Cu} / \mathrm{MgO}$ catalyst. Chem. Phys. Lett. 409(1-3), 89-92 (2005)

Tao, X.Y., Zhang, X.B., Zhang, L., Cheng, J.P., Liu, F., Luo, J.H., Luo, Z.Q., Geise, H.J.: Synthesis of multi-branched porous carbon nanofibers and their application in electrochemical double-layer capacitors. Carbon 44(8), 1425-1428 (2006)

Terzyk, A.P., Gauden, P.A., Furmaniak, S., Wesołowski, R.P., Harris, P.J.F., Kowalczyk, P.: Ar, CCl4 and C6H6 adsorption outside and inside of the bundles of multi-walled carbon nanotubes: simulation study. Phys. Chem. Chem. Phys. 11, 4982-4995 (2009)

Thakur, D.B., Tiggelaar, R.M., Gardeniers, J.G.E., Lefferts, L., Seshan, K.: Carbon nanofiber based catalyst supports to be used in microreactors: synthesis and characterization. Chem. Eng. J. 160(3), 899-908 (2010)

Toth, A., Torocsik, A., Tombacz, E., Laszlo, K.: Competitive adsorption of phenol and 3-chlorophenol on purified MWCNTs. J. Colloid Interface Sci. 387(1), 244-249 (2012)

Toth, A., Torocsik, A., Tombacz, E., Olah, E., Heggen, M., Li, C., Klumpp, E., Geissler, E., Laszlo, K.: Interaction of phenol and dopamine with commercial MWCNTs. J. Colloid Interface Sci. 364(2), 469-475 (2011)

Tu, J.P., Zhu, L.P., Hou, K., Guo, S.Y.: Synthesis and frictional properties of array film of amorphous carbon nanofibers on anodic aluminum oxide. Carbon 41(6), 1257-1263 (2003)

Wang, Z., Zhao, Z., Qiu, J.: Synthesis of branched carbon nanotubes from coal. Carbon 44(7), 1321-1324 (2006)

Wang, J.P., Yang, H.C., Hsieh, C.T.: Adsorption of phenol and basic dye on carbon nanotubes/carbon fabric composites from aqueous solution. Sep. Sci. Technol. 46(2), 340-348 (2011)

Wiśniewski, M., Werengowska-Ciećwierz, K., Terzyk, A.P.: New findings on the influence of carbon surface curvature on energetics of benzene adsorption from aqueous solutions. Chem. Phys. Lett. 619, 219-222 (2015)

Yamada, T., Maigne, A., Yudasaka, M., Mizuno, K., Futaba, D.N., Yumura, M., Iijima, S., Hata, K.: Revealing the secret of waterassisted carbon nanotube synthesis by microscopic observation of the interaction of water on the catalysts. Nano Lett. 8(12), 4288-4292 (2008)

Yamada, Y., Hosono, Y.K., Murakoshi, N., Higashi, N.O., Ichi-Oka, H.A., Miyake, T., Ikenaga, N.O., Suzuki, T.: Carbon nanofiber formation on iron group metal loaded on $\mathrm{SiO}$. Diam. Relat. Mater. 15(4-8), 1080-1084 (2006) 
Yang, K., Wu, W., Jing, Q., Zhu, L.: Aqueous adsorption of aniline, phenol, and their substitutes by multi-walled carbon nanotubes. Environ. Sci. Technol. 42(21), 7931-7936 (2008)

Yasuda, S., Futaba, D.N., Yamada, T., Satou, J., Shibuya, A., Takai, H., Arakawa, K., Yumura, M., Hata, K.: Improved and large area single-walled carbon nanotube forest growth by controlling the gas flow direction. ACS Nano 3(12), 4164-4170 (2009)
Zhao, B., Futaba, D.N., Yasuda, S., Akoshima, M., Yamada, T., Hata, K.: Exploring advantages of diverse carbon nanotube forests with tailored structures synthesized by supergrowth from engineered catalysts. ACS Nano 3(1), 108-114 (2009) 